\title{
CONFORTO AMBIENTAL EM EDIFICAÇÕES: OFERTA DO COMPONENTE CURRICULAR NOS CURSOS DE GRADUAÇÃO EM ENGENHARIA CIVIL DO BRASIL
}

Gleidson Martins da Costa - engcivil.gleidson@gmail.com Escola Politécnica de Pernambuco, Programa de Pós-graduação em Engenharia Civil Rua Benfica, 455 - Madalena

50720-001-Recife - PE

Felipe Guilherme Melo-felipe.guilherme@univasf.edu.br Universidade Federal do Vale do São Francisco, Campus Salgueiro Rua Antônio Figueira Sampaio, 134 - Nossa Sra. de Graças 56980-000 - Salgueiro - PE

Resumo: Na última década, o Brasil passou por um intenso processo de construção de moradias para combater o déficit habitacional, entretanto, estudos revelam que problemas no conforto ambiental dessas edificações têm sido recorrentes. Paralelamente, observa-se que os atores da construção civil têm valorizado questões como o cumprimento de prazos e a redução de custo em detrimento da qualidade do conforto dos usuários das edificações. Essa mentalidade é notada também na atuação de muitos engenheiros civis, que não enxergam o conforto ambiental como um agregador de valor para as habitações. Diante disso, este trabalho busca investigar como o tema Conforto Ambiental tem sido abordado nos cursos de Engenharia Civil das IES públicas brasileiras, baseando-se na análise dos projetos pedagógicos dos cursos (PPCs). Para tanto, tem-se uma pesquisa caracterizada como exploratória-descritiva, amparada na pesquisa documental e baseada na amostragem estratificada para seleção dos 129 cursos de Engenharia Civil estudados. Os resultados indicaram que nestes cursos a oferta de disciplinas específicas para tratar sobre a temática é pequena (27\%), sendo, na maioria deles, um componente curricular não obrigatório. Além disso, foi constatado que os aspectos do conforto ambiental não são tratado com a profundidade necessária. Posto isso, sugerem-se mudanças nos PPCs objetivando desenvolver, nos graduandos e futuros engenheiros civis, uma maior atenção e compreensão sobre a problemática.

Palavras-chave: Conforto Ambiental. Educação em Engenharia. Engenharia Civil. Matriz curricular. Projeto Pedagógico do Curso.

\section{INTRODUÇÃO}

Em 2006, estimava-se que o Brasil tinha um déficit de cerca de 7,9 milhões de domicílios distribuídos nas zonas rural e urbana (BRASIL, 2009). Para minimizar esse problema, foram elaboradas medidas para ampliar a oferta e facilitar a aquisição de moradias. À título de ilustração, cita-se o lançamento do Programa de Aceleração do Crescimento (PAC) Saneamento e Habitação, uma política fiscal expansiva que buscou estimular o crescimento sustentável por meio do investimento em projetos de infraestrutura e desenvolvimento econômico (FRANCO, 2012); e o Programa Minha Casa Minha Vida (MCMV), cuja meta era colaborar com a extinção do déficit habitacional no país (FRANÇA, 2012). O MCMV já entregou 4,1 milhões de unidades habitacionais, estando contratada a construção de 1,4 milhão de novas moradias (BRASIL, 2019). 
Apesar do avanço desses programas e da contribuição inestimável para a melhoria de vida da população, estudos publicados nos últimos anos acerca das Habitações de Interesse Social (HIS) têm ressaltado problemas nas condições de habitabilidade, principalmente no conforto ambiental dos domicílios, os quais ficam evidentes aos usuários que passam a habitar essas unidades (LINCK, 2013; BRAGA, 2013).

O conforto ambiental diz respeito ao conjunto de condições do ambiente que permitem aos indivíduos sentirem bem-estar térmico, visual, acústico e antropométrico, bem como propiciar a qualidade do ar e o conforto olfativo (LAMBERTS; DUTRA; PEREIRA, 2014).

Sobreira e Félix (2013) ressaltam que os modelos propostos para as HIS no Brasil estão, geralmente, relacionados à produção em massa e ao desenvolvimento de novas tecnologias e sistemas construtivos, priorizando a economia da produção em série. Consequentemente, a qualidade de vida dos usuários é negligenciada. Nesse contexto, a replicação de modelos de conjuntos habitacionais em diferentes localidades, mantendo as especificidades dos projetos, afeta negativamente a qualidade de vida, ou seja, as questões relacionadas ao conforto térmico, acústico e lumínico proporcionado pelo ambiente construído (ROSA, 2008; MOTA, CUNHA, 2016).

Kovaleski e Schmid (2009) atribuem a responsabilidade deste problema a diversos atores da indústria da construção civil, principalmente aos construtores, que priorizam outros aspectos relativos à execução da obra, tais como a melhoria dos índices de produtividade, diminuição de desperdício, cumprimento de prazos e, principalmente, a redução de custo em detrimento das soluções que buscam melhorar a qualidade e a sensação de conforto nos ambientes. Em outras palavras, as soluções para o conforto ambiental nas edificações são vistas como empecilhos e gastos desnecessários a serem minimizados (KOVALESKI; CAPRARO, 2008). Essa interpretação equivocada acerca do tema leva os profissionais do ramo da construção civil a desconsiderar a importância desse aspecto, bem como a associá-lo de maneira equivocada à elevação dos custos gerais da habitação.

De acordo com estudos realizados por Kovaleski e Capraro (2008), parte do preconceito notado nos engenheiros civis em relação ao conforto ambiental no ambiente construído se origina nos projetos pedagógicos dos respectivos cursos de graduação. Os autores afirmam que, geralmente, as grades curriculares dos cursos não preveem componentes curriculares que abordem o tema conforto ambiental com a profundidade necessária e, quando o fazem, abordam de maneira fragmentada nas ementas de diversas disciplinas ao longo do curso, sem a necessária ênfase entre teoria e prática (KOVALESKI; SCHMID, 2009).

Diante do exposto, este trabalho visa investigar como o ensino do conforto ambiental tem sido trabalhado nos currículos dos cursos de Engenharia Civil ofertados por Instituições de Ensino Superior (IES) públicas no Brasil. Com este estudo, espera-se contribuir com as discussões sobre o tema "Conforto Ambiental" no âmbito dos cursos de Engenharia Civil, enfatizando sua importância na formação e atuação do engenheiro. Além disso, tem-se a expectativa que as considerações trazidas aqui possam assistir coordenadores e Núcleos Docentes Estruturantes na adequação dos currículos dos seus respectivos cursos.

\section{PROCEDIMENTOS METODOLÓGICOS}

Nesta seção é apresentada a caracterização metodológica desta pesquisa. No que se refere à natureza, tem-se uma pesquisa aplicada ao passo que se busca propor soluções para um problema específico, com vistas a gerar resultados práticos (GIL, 2019). Quanto ao objetivo, tem-se uma pesquisa documental do tipo exploratória-descritiva (LAKATO, 2003). Desta maneira, descrevem-se características dos PPCs para proporcionar uma maior familiaridade a respeito da oferta e abordagem dos conceitos de conforto ambiental nos cursos de Engenharia 
Civil do país (GIL, 2008). Como fonte de informação primária, contou-se com os documentos escritos, sendo estes os PPCs, matrizes curriculares e ementários dos cursos, obtidos por meio da busca nas páginas eletrônicas oficiais das universidades e dos cursos. Acrescenta-se que a abordagem do presente estudo é mista (CRESWELL, 2010), amparada em procedimento de amostragem para seleção dos cursos e, posteriormente, na análise documental dos PPCs. O plano amostral, a coleta dos PPCs e as suas análises foram conduzidos durante os meses de abril e maio de 2020.

\subsection{Planejamento amostral}

O planejamento amostral pormenoriza os métodos utilizados para seleção e controle da amostra, bem como a avaliação da qualidade das suas estimativas. Esses métodos consistem em operações lógicas que asseguram o rigor científico das informações coletadas e das conclusões inferidas (SILVA, 2015). Além disso, este planejamento viabiliza a condução do levantamento a partir da delimitação da amostra e das suas características.

Para Silva (2015, p. 25), "o levantamento por amostragem permite a obtenção de informações a respeito de valores populacionais desconhecidos, por meio da observação de apenas uma parte (amostra) do seu universo (população)". Esse tipo de levantamento é planejado com vistas a facilitar a operacionalização da coleta de dados, minimizando aspectos como o tempo de coleta e os recursos pessoais e financeiros envolvidos, sem prejudicar a validade e a confiabilidade dos resultados.

Considerando as características da população (cursos de graduação em Engenharia Civil ofertados por IES públicas brasileiras), optou-se pela realização da amostragem estratificada. Tendo como objetivo melhorar a precisão das estimativas, Bolfarine e Bussab (2005, p. 93) ressaltam que "[...] a amostragem estratificada consiste na divisão de uma população em grupos (chamados estratos) segundo alguma(s) característica(s) conhecida(s) na população sob estudo, e de cada um desses estratos são selecionadas amostras em proporções convenientes." Em adição, Barbetta (1999) ressalta que esse tipo de amostragem garante que cada elemento da população tenha a mesma probabilidade de ser incluído na amostra. Neste estudo, para que os resultados apontem o panorama nacional do tema estudado, utilizaram-se como estratos as cinco regiões do Brasil. A Tabela 1 detalha o plano amostral do estudo.

A população-alvo deste estudo compreende o total de 177 cursos, extraídos do sistema eMEC (BRASIL, 2020) e selecionados conforme os seguintes critérios de inclusão: (i) cursos em atividade, logo, foram desconsiderados os cursos extintos e em extinção; (ii) cursos ofertados por IES públicas (Federal, Estadual ou Municipal); e (iii) cursos sem ênfase em áreas específicas, logo, foram excluídos os cursos de Engenharia Civil Costeira e Portuária, Engenharia Civil de Infraestrutura e Engenharia Civil Empresarial.

Tabela 1 - Plano amostral do estudo

\begin{tabular}{lcc}
\hline Estratos & Quant. de cursos $(\boldsymbol{n})$ & Tamanho da amostra \\
\hline Norte & 21 & 18 \\
Nordeste & 54 & 35 \\
Centro-Oeste & 24 & 20 \\
Sudeste & 49 & 33 \\
Sul & 29 & 23 \\
\hline Total de cursos & $\mathbf{1 7 7}$ & $\mathbf{1 2 9}$ \\
\hline Nota: Adotou-se um erro amostral tolerável de 0,1, com 95\% de confiabilidade. \\
\hline
\end{tabular}

Conforme recomendado por Rojas Soriano (2004) e Silva (2015), o tamanho de amostra de cada estrato foi calculado com base na amostragem aleatória simples. Dentro de cada 
estrato, os cursos incluídos na amostra foram sorteados aleatoriamente, considerando como índice de identificação o código de cada curso, conforme registro no e-MEC (BRASIL, 2020).

\subsection{Orientações para análise documental}

Os cursos foram separados em três grupos: (1) os que ofertam disciplina específica de conforto ambiental, (2) os que abordam algo sobre o tema conforto em algum componente curricular e (3) os que não trabalham a temática.

Para o primeiro grupo, seguiram-se os seguintes procedimentos: No primeiro momento, foi verificada a matriz curricular de cada curso para identificar se havia a disciplina de Conforto. Desta forma, buscou-se pelo referente termo nas matrizes curriculares, incluindo o nome das disciplinas e suas respectivas ementas.

$\mathrm{Na}$ sequência, verificou-se no ementário dos demais componentes curriculares se havia alguma disciplina que abordava sobre o tema no seu conteúdo, mesmo sem utilizar a palavra "conforto" explicitamente. Para ajudar na busca, além das expressões derivadas da palavra "Conforto" (Ambiental, Térmico, Acústico e Lumínico), foram definidos termos-chave que geralmente estão associadas ao conforto das edificações: Desempenho Ambiental, ABNT NBR 15.575, Conforto Humano e Conforto do Usuário; Conforto Higrotérmico, Condicionamento Térmico, Bioclimatologia, ABNT NBR 15.220, Ventilação (natural ou artificial), Insolação, Desempenho Acústico/Sonoro, Acústica arquitetônica, Resposta Humana ao Som e Ruído, Desempenho Lumínico/Visual e Iluminação Natural/Artificial.

Nesse panorama, para considerar que o tema era abordado na disciplina, definiu-se que ela deveria conter em sua ementa, pelo menos, um dos termos acima, considerando sempre a sua aplicação ao contexto da qualidade ambiental do interior das edificações.

Devido ao limite de páginas, este trabalho foca apenas na análise dos cursos que possuem a disciplina de Conforto. Assim sendo, discutem-se aspectos relacionados à oferta da disciplina, ao caráter de obrigatoriedade, à carga horaria e à ênfase dada ao conteúdo.

\section{RESULTADOS E DISCUSSÃO}

Após a definição da amostra, cuja base de dados está disponível em Costa e OliveiraMelo (2020), foi possível fazer uma breve caracterização das instituições selecionadas aleatoriamente.

No que diz respeito à organização, 91 (70\%) são públicas federais, 24 (19\%) estaduais, 9 (7\%) municipais e 5 (4\%) públicas cujas mantenedoras são autarquias ou fundações municipais. No que tange à categoria, observou-se que $84(65 \%)$ são Universidades, $32(25 \%)$ Institutos Federais de Educação, Ciência e Tecnologia, 8 (6\%) Centros Universitários, 3 (2\%) Faculdades e 2 (2\%) Centros Federais de Educação Tecnológica.

Antes de aprofundar a discussão, ressalta-se que não foi possível ter acesso a todos os dados desejados, tendo em vista que alguns cursos não disponibilizavam os PPCs, matrizes curriculares e/ou ementas em suas páginas virtuais. Assim sendo, os cursos que não participaram das análises por impossibilidade de acesso aos referentes dados foram: UNEMAT (1442539), UEMA (11880), UEMA (1404083), UTFPR (14543), UTFPR (1103606), UNIUV (1516296) e UEA (1486209). Nesse sentido, dentre os 129 cursos inclusos na amostra, 96,6\% (122 cursos) passaram pela análise documental.

Analisando, assim, a realidade dos cursos de Engenharia Civil do país, a partir da leitura das matrizes curriculares, verificou-se a presença de 42 disciplinas relacionada ao Conforto nas Edificações (Tabela 2). 
Tabela 2 - Dados das disciplinas de conforto ofertadas pelas IES públicas brasileiras.

\begin{tabular}{|c|c|c|c|c|c|c|}
\hline Código & IES & Disciplina & Caráter & \multicolumn{2}{|c|}{ CH/Perfil } & Região \\
\hline 1128355 & UFMS & 1. Conforto em Edificações & $\mathrm{N}-\mathrm{O}$ & 51 & S.D. & \multirow{4}{*}{$\begin{array}{l}\text { Centro- } \\
\text { Oeste }\end{array}$} \\
\hline 15837 & UFMS & 2. Conforto em Edificações & $\mathrm{N}-\mathrm{O}$ & 51 & S.D. & \\
\hline 1187682 & IF Goiano & $\begin{array}{l}\text { 3. Edifícios Sustentáveis: Clima e Conforto } \\
\text { Humano }\end{array}$ & $\mathrm{N}-\mathrm{O}$ & 40 & $\mathrm{~T}$ & \\
\hline 3 & UFMT & 4. Conforto Ambiental & $\mathrm{N}-\mathrm{O}$ & 60 & S.D. & \\
\hline 1457169 & IFPB & 5. Conforto Ambiental & $\mathrm{N}-\mathrm{O}$ & 50 & $\mathrm{~T}$ & \\
\hline 1481756 & CESA & $\begin{array}{l}\text { 6. Edifícios Sustentáveis, Clima e Conforto } \\
\text { Humano }\end{array}$ & $\mathrm{N}-\mathrm{O}$ & 30 & S. D. & \\
\hline 1146746 & AESGA & 7. Edifícios Sustentáveis, clima e Conforto & $\mathrm{N}-\mathrm{O}$ & 60 & S.D & Nordeste \\
\hline & & 8. Arquitetura e Conforto Ambiental & $\mathrm{O}$ & 30 & T-P & \\
\hline 1151164 & UFAL & 9. Conforto Luminoso & $\mathrm{N}-\mathrm{O}$ & 30 & $\mathrm{~T}$ & \\
\hline & & 10. Conforto Térmico & $\mathrm{N}-\mathrm{O}$ & 30 & $\mathrm{~T}$ & \\
\hline 1262709 & UFLA & 11. Conforto Térmico em Edificações & $\mathrm{N}-\mathrm{O}$ & 34 & $\mathrm{~T}$ & \\
\hline 1122890 & UNIFEI & $\begin{array}{l}\text { 12. Conforto Térmico e Acústico em } \\
\text { Edificações }\end{array}$ & $\mathrm{O}$ & 64 & T-P & \\
\hline & JECD & 13. Conforto Térmico & $\mathrm{N}-\mathrm{O}$ & 47,5 & $\mathrm{~T}$ & \\
\hline 1201049 & ІГगГ & 14. Conforto Acústico & $\mathrm{N}-\mathrm{O}$ & 47,5 & $\mathrm{~T}$ & \\
\hline 15350 & UNITAU & 15. Conforto Ambiental & $\mathrm{O}$ & 80 & $\mathrm{~T}$ & \\
\hline 689 & UFV & 16. Comportamento Ambiental I & $\mathrm{N}-\mathrm{O}$ & 60 & T-P & Sudeste \\
\hline 089 & $0 \mathrm{r}$ & 17. Comportamento Ambiental II & $\mathrm{N}-\mathrm{O}$ & 60 & $\mathrm{~T}-\mathrm{P}$ & \\
\hline 1105973 & UFTM & 18. Conforto Ambiental & $\mathrm{N}-\mathrm{O}$ & 60 & $\mathrm{~T}$ & \\
\hline 1103225 & UFVJM & 19. Conforto Ambiental & $\mathrm{N}-\mathrm{O}$ & 60 & S.D. & \\
\hline & & 20. Conforto Ambiental I & $\mathrm{N}-\mathrm{O}$ & 45 & T-P & \\
\hline 12954 & UFMG & 21. Conforto Ambiental II & $\mathrm{N}-\mathrm{O}$ & 45 & T-P & \\
\hline & & 22. Conforto Ambiental III & $\mathrm{N}-\mathrm{O}$ & 45 & T-P & \\
\hline 3668 & FURB & 23. Arquitetura e Conforto Ambiental & $\mathrm{O}$ & 36 & T-P & \\
\hline 1442124 & UDESC & $\begin{array}{l}\text { 24. Conforto Térmico e Acústico das } \\
\text { Construções }\end{array}$ & $\mathrm{N}-\mathrm{O}$ & 72 & $\mathrm{~T}$ & \\
\hline 1038 & FURG & 25. Conforto Térmico de Edificações & $\mathrm{N}-\mathrm{O}$ & 30 & S.D. & \\
\hline 1102403 & UFTPR & 26. Conforto Ambienta I & $\mathrm{N}-\mathrm{O}$ & 36 & T-P & \\
\hline 1102405 & 促 & 27. Conforto Ambiental 2 & $\mathrm{~N}-\mathrm{O}$ & 36 & T-P & \\
\hline 1265866 & IFSul & 28. Conforto Ambiental & $\mathrm{N}-\mathrm{O}$ & 90 & S.D. & \\
\hline 1111700 & UTFPR & 29. Conforto Ambiental & $\mathrm{N}-\mathrm{O}$ & 72 & T-P & \\
\hline 14724 & UNIOESTE & $\begin{array}{l}\text { 30. Conforto Térmico e Acústico em } \\
\text { Edificações }\end{array}$ & $\mathrm{O}$ & 51 & T-P & Sul \\
\hline 150159 & JFM & $\begin{array}{l}\text { 31. Conforto Ambiental para Engenharia } \\
\text { Civil }\end{array}$ & $\mathrm{O}$ & 34 & $\mathrm{~T}$ & \\
\hline (150109 & OLIVI & $\begin{array}{l}\text { 32. Lab. de Conforto Ambiental para } \\
\text { Engenharia Civil }\end{array}$ & $\mathrm{O}$ & 17 & $\mathrm{P}$ & \\
\hline 42559 & UEL & 33. Conforto Ambiental & $\mathrm{O}$ & 60 & T-P & \\
\hline & & $\begin{array}{l}\text { 34. Conforto Ambiental para Engenharia } \\
\text { Civil }\end{array}$ & $\mathrm{O}$ & 34 & $\mathrm{~T}$ & \\
\hline 3402 & UEM & $\begin{array}{l}\text { 35. Lab. de Conforto Ambiental para } \\
\text { Engenharia Civil }\end{array}$ & $\mathrm{O}$ & 17 & $\mathrm{P}$ & \\
\hline 16901 & UFRR & 36. Conforto Térmico de Edificações & $\mathrm{N}-\mathrm{O}$ & 60 & $\mathrm{~T}$ & \\
\hline 63313 & UEA & 37. Conforto Ambiental & $\mathrm{N}-\mathrm{O}$ & 60 & S.D & \\
\hline 1262444 & $\mathrm{NI}$ & 38. Conforto Ambiental I & $\mathrm{N}-\mathrm{O}$ & 34 & T-P & \\
\hline 1202444 & UNIFESSPA & 39. Conforto Ambiental II & $\mathrm{N}-\mathrm{O}$ & 34 & T-P & Norte \\
\hline 1161306 & IFTO & 40. Conforto Térmico & $\mathrm{N}-\mathrm{O}$ & 80 & T-P & \\
\hline 1267522 & UNIFAP & 41. Conforto Ambiental & $\mathrm{O}$ & 45 & $\mathrm{~T}$ & \\
\hline 116727 & UNIR & 42. Conforto nas Edificações & $\mathrm{N}-\mathrm{O}$ & 60 & $\mathrm{~T}$ & \\
\hline $\begin{array}{l}\text { Conf. } \\
\text { Conf. }\end{array}$ & $\begin{array}{l}\text { bienta } \\
\text { mico }\end{array}$ & $\begin{array}{l}\mathrm{T}=\text { Aula teórica } \\
\mathrm{T}-\mathrm{P}=\text { Aula teórica }\end{array}$ & ca & lla prá & & \\
\hline
\end{tabular}

De antemão, salienta-se que não existe um marco legislativo que regulamenta a oferta da disciplina ou a abordagem do conteúdo Conforto Ambiental nos cursos de Engenharia Civil. De forma abrangente, as Diretrizes Curriculares dos Cursos de Engenharia (BRASIL, 2019) apenas enfatizam que os profissionais de engenharia devem ser capaz de reconhecer as necessidades dos usuários, formular, analisar e resolver, de forma criativa, os problemas de Engenharia; além de atuar com isenção e comprometimento com a responsabilidade social e com o desenvolvimento sustentável. 
No contexto normativo, acredita-se que o tema foi citado pela primeira vez nos Referenciais Curriculares Nacionais dos Cursos de Bacharelado e Licenciatura (BRASIL, 2010). Nesses moldes, o presente documento destaca Bioclimatismo, Conforto Térmico, Sonoro e Luminoso como tópicos a serem abordados na formação do engenheiro civil. É necessário explicar que os referenciais curriculares não limitam as instituições e os cursos quanto a elaboração dos PPCs, assumindo mais um caráter norteador à medida em que buscam corrigir assimetrias presentes nos cursos de ensino superior brasileiros. Essas questões supracitadas devem influenciar na inserção do assunto PPCs de Engenharia Civil do país, logo, traz implicações na proporção da oferta da disciplina averiguada neste estudo.

Conforme mostrado na Tabela 2, as 42 disciplinas identificadas se encontram distribuídas em 33 cursos e 30 IES distintas. Nesse cenário, percebe-se que dos 122 cursos analisados, ou seja, que disponibilizavam a matriz curricular, apenas $27 \%$ possuem pelo menos uma disciplina específica sobre Conforto nas Edificações.

Em pesquisa realizada por Kovaleski (2009), para verificar a oferta da disciplina de Conforto Ambiental pelas universidades federais com curso de Engenharia Civil no Brasil, verificou-se que apenas três das 22 principais IES ofertavam o referente componente curricular $(18,7 \%)$. No caso, seis delas não tinham a matriz curricular disponível nas suas páginas eletrônicas.

Comparando os resultados encontrados neste trabalho com os de Kovaleski (2009), percebe-se que nos últimos anos houve uma mudança na estruturação dos projetos pedagógicos de algumas IES federais, como é o caso da UFMT e UFMS, que passaram a incorporar uma disciplina específica sobre Conforto Ambiental. Além disso, alguns cursos passaram a disponibilizar os seus PPCs virtualmente, à exemplo da UFRR.

Apesar da inclusão da disciplina, infere-se que o componente curricular tem um caráter, majoritariamente, não obrigatório. Das 42 disciplinas encontradas, apenas 11 (26,2\%) têm caráter obrigatório. Em termos gerais, isso representa que somente em 6,6\% dos cursos que foram analisados (122), os alunos têm, indispensavelmente, uma disciplina exclusiva para aprender sobre o conforto no ambiente construído. Considerando a importância do tema, esse percentual é irrisório e sinaliza a necessidade de cursos readequarem suas matrizes curriculares.

Diante disso, se considerado que o contato com assunto ocorre de maneira aprofundada especificamente nestas disciplinas, acredita-se que parte dos graduandos saem do curso sem aprender conceitos importantes que podem mudar/influenciar na forma com que os profissionais da construção civil veem as habitações, principalmente, porque os estudantes de engenharia possuem maior resistência em mudar de opinião sobre o conforto ambiental. Isto foi apontado em estudo desenvolvido com alunos do curso de engenharia civil do curso técnico em edificações e vendedores de matérias de construção, no qual se conclui que os primeiros têm maior dificuldade de enxergar o valor agregado na edificação que possui melhores condições ambientais, mesmo após eles serem expostos a experimentos que demonstravam as influências das condições climáticas no conforto interno dos edifícios (KOVALESKI; SCHMID, 2009).

Ainda sobre a Tabela 2, percebe-se que os cursos possuem maneiras distintas de organizar a distribuição do conteúdo nos componentes curriculares, evidenciando-se três tipos de formatação. O primeiro formato, mais frequente, têm características abrangentes na medida em que em seu conteúdo é abordado sobre os três quesitos de conforto no ambiente construído (térmico, lumínico e acústico), correspondendo à metade (50\%) do total das disciplinas de conforto encontradas nos documentos revisados. O segundo tipo foca somente em um dos três tópicos, sendo: $9(21,4 \%)$ direcionadas ao conforto térmico, $3(7,1 \%)$ específicas sobre conforto acústico e $2(4,8 \%)$ exclusivas de conforto lumínico. O terceiro formato observado 
associa dois aspectos do conforto ambiental em um único componente curricular, sendo organizadas e distribuídas da seguinte maneira: 5 (11,9\%) abordam o conforto térmico e acústico, $1(2,4 \%)$ trata acústico e visual e $1(2,4 \%)$ térmico e lumínico.

Segundo Neves e Ruchel (2016), nos cursos de Arquitetura e Urbanismo, as três estruturas mais utilizadas para apresentar o assunto são: a) oferta de duas disciplinas, sendo uma introdutória e outra de aprofundamento; b) três disciplinas obrigatórias, cada uma tratando sobre uma temática específica do conforto; e c) quatro disciplinas obrigatórias, sendo um mais generalista e introdutória, enquanto as demais focam em um aspecto. Estas estruturações permitem contemplar os três aspectos do conforto ambiental, bem como realizar o aprofundamento sobre os assuntos, logo, devem servir como exemplos para melhoria dos PPCs dos cursos de Engenharia Civil. Dessa forma, enfatiza-se que o objetivo não é reformular as matrizes curriculares dos cursos do Engenharia Civil nos moldes dos cursos de Arquitetura e Urbanismo. Pretende-se com essa discussão gerar direcionamentos para o aperfeiçoamento dos componentes curriculares já ofertadas nos cursos de engenharia civil e/ou a criação de componentes que abordem suficientemente o tema Conforto Ambiental.

Dentre os cursos de Engenharia Civil analisados, apenas um (UFMG) possui estruturação similar à sugerida por Neves e Ruchel (2016), separando três disciplinas para lecionar em cada uma delas a respeito de uma das problemáticas do conforto ambiental. Em contrapartida, verificou-se em alguns cursos a preferência por trabalhar somente um ou dois dos aspectos do conforto ambiental. Este fato é percebido, respectivamente, nos cursos da UFRR, que leciona somente conforto térmico, e UEL, que não inclui tópicos sobre o conforto lumínico na disciplina. Não se sabe a justificativa para tais estruturações, mas é algo que deve ser refletido, pensando na formação e atuação do Engenheiro Civil.

Corbella e Yannas (2009) ressaltam que o projetista de uma edificação deve considerar todas as questões do ambiente, ou seja, não faz sentido projetar um edifício que possua boas condições de conforto térmico, mas que gere desconforto acústico e visual para os usuários. Assim, as decisões tomadas para solucionar cada problema da edificação devem ser integradas, propiciando boas condições de conforto ambiental. Outrossim, é preciso que o estudante entenda a relação de interdependência entre os aspectos do conforto ambiental nas edificações e suas implicações na qualidade de vida dos usuários.

Em razão disso, mesmo havendo um direcionamento na proposta curricular, ressalta-se a necessidade de informar aos discentes sobre a importância das demais questões do conforto ambiental, visto que ter uma visão holística e humanista e atuar com comprometimento com o desenvolvimento sustentável são algumas das características esperadas no perfil do egresso dos cursos de graduação em Engenharia (BRASIL, 2019).

Na mesma perspectiva, Souza et al. (2015) enfatizam que o ramo da construção civil é um dos que mais cresce, bem como é um dos que mais contribui para o desenvolvimento social e econômico. Paralelamente, provoca grandes impactos ambientais. Desta maneira, desenvolver a responsabilidade ambiental é imprescindível para a formação dos engenheiros civis. Nesse ínterim, os autores citam que essa responsabilidade pode ser desenvolvida de diversas formas como, por exemplo, através de inovações que contribuam com a eficiência energética, a redução da poluição e o planejamento de construções sustentáveis, visando, principalmente, ao conforto dos usuários.

Retomando a análise das disciplinas, no que tange à distribuição da carga horária, tem-se em média a dedicação de, aproximadamente, 48 horas para a disciplina, o equivalente a três créditos. As cargas horárias mínimas (17h) foram observadas nas disciplinas de Lab. de Conforto Ambiental para Engenharia Civil dos dois cursos da UEM, os únicos com presença de aulas laboratoriais. A carga horária máxima (90h) está no curso do IF Sul, que adota o regime anual. O tempo e a metodologia utilizados para lecionar o assunto de conforto 
ambiental devem ser bem planejados, pois nem sempre o conteúdo é assimilado por meio de aulas puramente teóricas. Kovaleski (2010) percebeu que aulas experimentais são eficazes no ensino do tema à medida que podem contribuir para a mudança de visão dos profissionais da construção civil. Todavia, o autor cita que tais atividades demandam tempo, espaço adequado e equipamentos apropriados.

Nos PPCs também foi observada a distribuição das horas-aula. Em 16 dos componentes $(38,1 \%)$, a carga horária está dividida em aulas teóricas e práticas; em 15 realizadas apenas aulas teóricas $(35,7 \%)$; e, exclusivamente, as aulas práticas são aplicadas nas duas disciplinas de laboratório $(4,8 \%)$. À luz desses dados, infere-se que ainda há uma necessidade de laboratórios, onde possam ser realizadas práticas construtivas, simulações e testagens alternativas antes de inserir o profissional no canteiro de obras (KOVALESKI; CAPRARO, 2008). Nos demais cursos $(9 ; 21,4 \%)$, não foram obtidas informações a respeito da distribuição da carga horária.

Por fim, como destacado na seção dos procedimentos metodológicos, observou-se a presença de tópicos relativos ao tema conforto ambiental no conteúdo de outros componentes curriculares, as quais não são analisadas neste estudo em razão da delimitação do objeto. Assim, reconhece-se que a abordagem do tema em outras disciplinas sugere uma variedade de estratégias utilizadas pelos cursos para tratar o assunto, o que deve ser aprofundado em um estudo sequente.

\section{CONSIDERAÇÕES FINAIS}

Estudos realizados nas Habitações de Interesse Social (HIS) têm notado a presença de problemas de habitabilidade, sendo a falta de conforto ambiental um problema recorrente. São vários os fatores que contribuem para esta realidade. Dentre eles, ressalta-se a desvalorização, por parte dos atores construção Civil, em relação à adoção de estratégias de melhoria do conforto ambiental para priorizar outras questões como o cumprimento de prazos e a redução de custo das obras. Os engenheiros civis e graduandos estão inseridos neste contexto.

Diante disso, este trabalho objetivou averiguar a questão da oferta da disciplina de Conforto Ambiental nos cursos de Engenharia Civil do Brasil, focando na análise dos PPCs dos cursos para propor mudanças sobre o tema. Assim, a pesquisa percebeu que ainda é pequena a oferta deste componente curricular, com menos de um terço dos cursos possuindo uma disciplina para tratar exclusivamente sobre o tema. Atrelada a esta baixa oferta, tem-se que a maioria das disciplinas ofertadas tem caráter optativo. Alguns cursos tendem a direcionar o conteúdo para um ou dois dos problemas relacionados ao conforto ambiental (térmico, acústico ou luminíco). Além disso, tem-se uma grande quantidade de disciplinas com carga horária unicamente teórica, sem práticas laboratoriais.

Em vista do cenário apresentado, espera-se que os cursos notem esta demanda e passem a inserir disciplinas específicas para tratar sobre a qualidade ambiental no espaço construído, despertando nos graduandos a importância de se construir edifícios com conforto térmico, acústico e lumínico. Desta maneira, acredita-se que seja possível contribuir com a formação de engenheiros civis mais responsáveis com as questões socioambientais e não apenas econômicas, tornando-os mais comprometidos com o desenvolvimento sustentável.

Ademais, sabe-se que a discussão do assunto não deve se esgotar com este estudo. Percebendo-se que o tema ou aspectos relacionados ao conforto ambiental encontram-se distribuídos em diferentes disciplinas ao longo do curso de Engenharia Civil, é importante que as estratégias empregadas em tais componentes curriculares sejam também verificadas. 


\section{REFERÊNCIAS}

ASSOCIAÇÃO BRASILEIRA DE NORMAS TÉCNICAS. NBR 15220-3: Desempenho Térmico de Edificações. Rio de Janeiro, 2005.

NBR 15.575: Edificações Habitacionais - Desempenho. Rio de Janeiro: ABNT, 2013.

BARBETTA, P. A. Estatística aplicada às ciências sociais. 3. ed. Florianópolis, SC: UFSC, 1999.

BOLFARINE, H.; BUSSAB, W. O. Elementos de Amostragem. São Paulo: Edgar Blücher, 2005.

BRAGA, M. N. A. Análise do conforto térmico em habitações de interesse social no Bairro Sumaré, Município de Sobral, Ceará. 133 f. Dissertação (Mestrado em Engenharia Civil) - Departamento de Engenharia Civil da Universidade Federal do Ceará, Fortaleza, 2013.

BRASIL. Ministério da Educação (MEC). Resolução CNE/CES 11/2002. Institui Diretrizes Curriculares Nacionais do Curso de Graduação em Engenharia. Disponível em:

http://portal.mec.gov.br/component/content/article?id=12991. Acesso em: 25 maio 2020.

BRASIL. Ministério das Cidades. Plano Nacional de Habitação. Brasília, 2009.

BRASIL. Ministério do Desenvolvimento Regional. Secretaria Nacional de Habitação. 2019. Disponível em: https://cbic.org.br/wp-content/uploads/2019/04/Apresenta\%C3\%A7\%C3\%A3o-MDR.pdf. Acesso em: 09 maio 2020.

BRASIL. Ministério da Educação - MEC. Sistema e-MEC 3 v. 5.381.0-6375. 2020. Disponível em: https://emec.mec.gov.br/. Acesso em: 10 maio 2020.

BRASIL. Ministério da Educação. Referenciais curriculares nacionais dos cursos de bacharelado e licenciatura. Brasília, 2010.

CORBELLA, O.; YANNAS, S. Em busca de uma arquitetura sustentável para os trópicos: Conforto Ambiental. 2. ed. Rio de Janeiro: Revan, 2009.

COSTA, G. M.; OLIVEIRA-MELO, F. G. Amostragem Aleatória de Cursos de Engenharia Civil ofertados por IES públicas brasileiras. [S.1.]: Base de dados. DOI: 10.5281/zenodo.4043721. 22 set. 2020

CRESWELL, J. W. Projeto de pesquisa: métodos qualitativos, quantitativos e misto. 3. ed. Porto Alegre: Artmed, 2010.

FRANCO, G. M. Programa de Aceleração - P.A.C. Discussão sociológica a respeito do Mercado da Habitação. Trabalho de Conclusão de Curso (Bacharelado em Economia) - Departamento de Economia, Universidade Estadual Paulista, São Paulo, 2012.

FRANÇA, K. Confederação Nacional de Municípios. Habitação: Política Nacional de Habitação. Brasília: CNM, 2012.

GIL, A. C. Métodos e técnicas de pesquisa social. 7. ed. São Paulo: Atlas, 2019.

GIL, A. C. Como elaborar projetos de pesquisa. 4. ed. São Paulo: Atlas, 2008.

KOVALESKI, A. C. Educação em conforto ambiental: Avaliação da percepção de três públicos-alvo e de duas técnicas didáticas. Dissertação (Mestrado em Construção Civil) - Setor de Tecnologia, Universidade Federal do Paraná, Curitiba, 2009.

KOVALESKI, A. C.; SCHMID, A. L. Educação em conforto ambiental: Avaliação da percepção de acadêmicos de engenharia civil e de duas técnicas de ensino. In: XXXVII Congresso Brasileiro de Ensino de Engenharia, 2009, Pernambuco. Anais. Recife, 2009. 
KOVALESKI, A. C.; CAPRARO, L. Conforto ambiental para estudantes de engenharia: Proposta de ensino. In: Congresso Brasileiro de Ensino de Engenharia, XXXVI, Anais, São Paulo 2008.

LAKATOS, E. M. Fundamentos de metodologia científica. 5. ed. São Paulo: Atlas, 2003.

LAMBERTS, R.; DUTRA, L.; PEREIRA, F. O. R. Eficiência Energética na Arquitetura. 3. ed. São Paulo: PW Gráfica e Edit. Associados LTDA, 2014. 366 p.

LINCK, G. I. Avaliação do Desempenho Higrotérmico de Habitação de Interesse Social em Santa Maria/RS. 2013. 235 f. Dissertação (Mestrado em Engenharia Civil) - Centro de Tecnologia da Universidade Federal de Santa Maria, Santa Maria, 2013.

MOTA, R. R. S.; CUNHA. E. G. Análise das condições de uso e ocupação de HIS, localizadas na cidade de Pelotas - ZB2, preconizadas no RTQ-R no método de simulação computacional. Cadernos de Pós-Graduação em Arquitetura e Urbanismo, São Paulo, v. 16, n. 2, p. 109 - 132, dez. 2016.

NEVES, L. O.; RUSCHEL, R. C. Um panorama sobre a temática do conforto ambiental. PARC, Campinas SP, v. 7, n. 4, p. 198-201, dez. 2016.

ROJAS SORIANO, R. Manual de pesquisa social. Petrópolis, RJ: Vozes, 2004.

ROSA, S. Indicadores de Sustentabilidade Urbana Aplicados em Conjuntos Habitacionais de Catalão/Goiás. 2008. 208 f. Dissertação (Mestrado em Arquitetura e Urbanismo) - Faculdade de Arquitetura e Urbanismo da Universidade de Brasília, Brasília, 2008.

SILVA, N. N. Amostragem probabilística: um curso introdutório. 3. ed. São Paulo, SP: EDUSP, 2015.

SOUZA, A. A. P.; PORTELA, B.D.; CORREA, M.P.; GOMES, C. A responsabilidade ambiental na formação do engenheiro civil. Revista do CEDS. São Luiz, v. 1, n 3, set. 2015.

SOBREIRA; F.; FELIX, B. Projeto de habitação social no Brasil: discurso e prática da sustentabilidade.

Universitas: Arquitetura e Comunicação Social, v. 10, n. 2, p. 23-35, jul./dez. 2013.

\title{
ENVIRONMENTAL COMFORT IN BUILDINGS: THE CURRICULAR COMPONENTE OFFER IN BRAZILIAN CIVIL ENGINEERING UNDERGRADUATION PROGRAMS
}

\begin{abstract}
In the last decade, Brazil has gone through an intense process of housing construction to combat the housing deficit. Studies reveal that problems in the environmental comfort of these buildings have been recurring. At the same time, it is observed that civil construction actors value issues such as meeting deadlines and reducing costs at the expense of the quality of comfort for users of buildings. This mentality is also noticed in the undergraduates of the civil engineering course, who do not see environmental comfort as an added value for housing. In view of this, the present work seeks to investigate how Environmental Comfort has been approached in the Civil Engineering courses offered by public higher education institutions in the country, based on the analysis of the pedagogical projects of the courses. This research is characterized as exploratory-descriptive and used stratified sampling to select the courses studied. The results indicated that, in the Civil Engineering courses, the offer of a specific discipline to deal with the theme is small (27\%), with most courses being a nonmandatory curricular component. In addition, it was found that one or two aspects of environmental comfort are usually covered in the course. That said, changes in the PPCs are suggested in order to develop, in the undergraduates and future civil engineers, an attention and understanding about the problem.
\end{abstract}

Keywords: Environmental comfort. Engineering Education. Civil Engineering. Curriculum. Program's Pedagogical Project. 